Fig. 1. Recency and primacy effects.

\section{DISCUSSION}

As in the Bernbach (1967) study, the groups that verbalized had higher recall scores than the group that did not. The fact that the WL group did as well as the $C L$ group implses that any sort of verbalization is helpful for recall. Another possible explanation of this, besides the rehearsal hypothesis, could be based on differential attention. Ss in the NL group had to have their attention directed towards the test stimuli several times during the session (at times it was questionable whether or not they were really trying to remember the stimuli). The fact that most of the Ss in the NL group scored at chance or below levels seems to confirm this implication. Labels of any kind may have served to keep Ss' attention focused on the stimuli.

Bernbach only observed recency and primacy effects in the group that used labels. In this study, the recency effects were observed for all groups, even the NL group. The NL group also displayed a strong primacy effect. These effects may be related to the decrease in the number of stimuli used. Bernbach used eight stimuli, while this experiment used only four. However, even with the eight stimuli, it seems probable that at least recency effects would be found in the NL group if $S$ was paying attention, since the recent exposure to the stimuli would strengthen his memory trace.

In the pilot study for this experiment, another experimental group was included. This group used CVCs as labels. The group was dropped from the experiment because of the difficulty the children had learning the CVC-color associations. The testing method used for the pilot study was similar to the method used by Bernbach, with 16 trials per $S$ and eight stimulus cards per trial. This was cut because the sessions proved to be too lengthy to keep the children's interest.

The results of this study indicate that, while verbalization does aid recall in children, the differences between the forgetting functions of adults and children cannot be completely explained by a rehearsal hypothesis or by differential attention. Neither one of these explanations accounts for the recency or primacy effects found in the NL group.

\section{RFFERENCES}

ATKINSON, R. C., BERNBACH, H. A, \& HANSEN, D. N. Short-term memory with young children. Psychonomic Science, 1964, $1,255-256$

BERNBACH. H. A. The effect of labels on short-term memory for colors with nursery school children. Psychonomic Science, 1967. 7. 149-150.

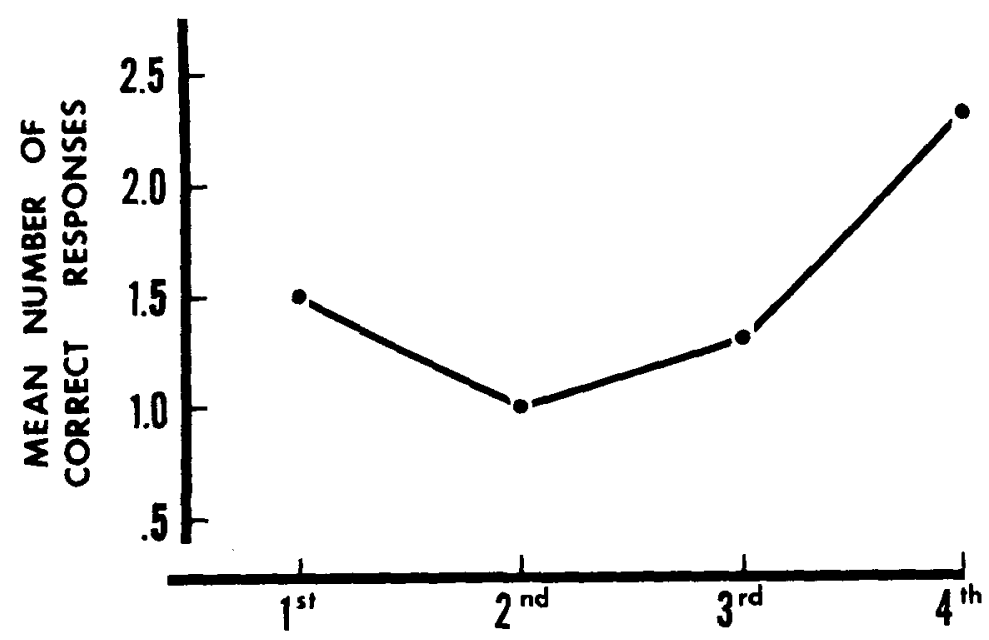

SERIAL POSITION

WINER, B. J. Statistical principles in experimental design. New York: McGraw-Hill, 1962.

1. This study was supported in part by a training grant in normal and retarded development, Grant HD 00244, from the National Institute of Child Health and Human Development, United States Public Health Service. Correspondence should be sent to Leslie B. Cohen, Psychology Department, University of. Illinois, Urbana, Ill. 61801.

\title{
Effect of luminance in probability learning ${ }^{1}$
}

JEANNE G. PORTER and HARRY $L$. MADISON, University of Wisconsin-Milwaukee, Milwaukee, Wis. 53201

Three groups of $40 \mathrm{Ss}$ predicted the occurrence of reinforcing lights differing in luminance in an Estes \& Straughan (1954) probability-learning situation. Little effect of luminance difference was found. It was concluded that the luminance effect reported by Nazzaro \& Todorov (1966) is, at most, a weak effect in this situation.

Nazzaro \& Todorov (1966) reported a preference in a two-choice probability-learning situation for predicting the brighter of two reinforcing lights, here called the "luminance effect." Using $12 \mathrm{Ss}$ per group over 200 trials, they found this effect when the brighter light occurred with $\pi=.75$ or .25 . It was not found when $\pi=.5$, but here they used only nine Ss per group. Madison \& Boudewyns (1967) reported a preference for predicting a single reinforcing light as compared to predicting no-light, called the "asymmetric effect," with $\pi=.5$ or .7 . They suggested that the asymmetric effect could be an extreme case of the luminance effect. This raises the interesting possibility of relating the physical properties of a reinforcing stimulus to the parameters in probability-learning theory (Estes \& Straughan, 1954). 
To test this hypothesis, Boudewyns \& Madison (in press) compared predictions of reintorcing lights differing in brightness, as well as predictions of occurrence or nonoccurrence of a single light. They clearly confirmed the asymmetric effect but found little evidence for the luminance effect, using $80 \mathrm{Ss}$ per group.

However, whereas Nazzaro \& Todorov tested each $S$ at only one $\pi$ value, Boudewyns \& Madison tested each $S$ first for 100 trials with $\pi=.5$, followed immediately by 140 trials with $\pi=.7$, the same procedure used by Madison and Boudewyns (1967). To investigate the possibility that the first series of trials, on which the lights of unequal luminance occurred with equal probability, somehow produced a response set that eliminated the luminance effect on the subsequent trials, the present study used the same apparatus and general procedures as did Boudewyns and Madison but tested each $S$ for 200 trials with a single $\pi$ value of .7. Three luminance conditions were compared. One, (BB) used two equally bright lights. The other two (BD and DB) used lights of unequal luminances. The luminance levels were the same as those used by Nazzaro and Todorov.

\section{METHOD}

The Ss were three groups of 40 right-handed, beginning psychology students, tested 1.4 Ss at a time. Each $S$ sat in a booth in front of a vertical panel, with a green signal light centered $10 \mathrm{in}$. above the table. Located symmetrically $2 \mathrm{in}$. below the signal light were two 1-1/8-in. apertures, $43 / 4$ in. apart, each illuminated by white light from behind, with the luminance adjusted to $3.2 \log \mathrm{ft}-\mathrm{L}$. A response key was located below each

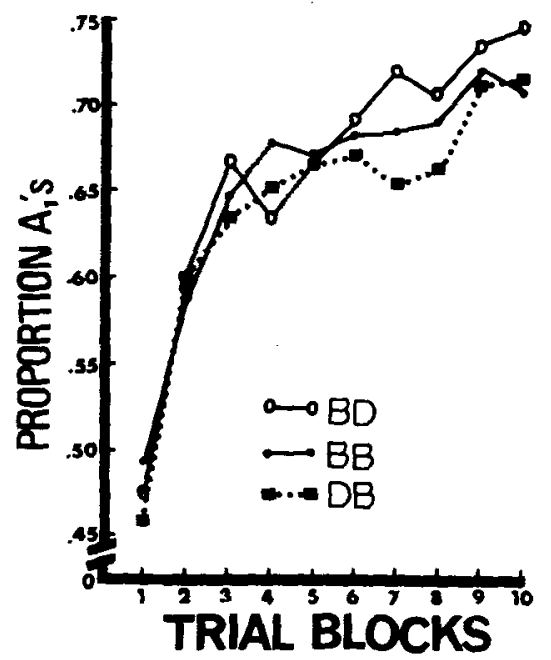

Fig. 1. Mean proportion of A1 responses per 20-trial block. aperture. For Condition BB, both apertures were covered by thin, clear plastic. For BD and $\mathrm{DB}$, one of the apertures was covered by a neutral-density filter that reduced the luminance by $1 \log$ unit. A modified IBM Summary Punch was used to control reinforcing events and record Ss' responses. Prepunched computer-generated random digits were read on each trial to cause one of the reinforcing events to occur, and the responses of the Ss were recorded on the punch-cards.

The Ss were dark-adapted for about 4 min, during which time taped instructions asked the $S s$ to predict the occurrence of one of the reinforcing lights on each trial following the signal by operating the corresponding response key. For each $S$ in Group BB, one of the lights was designated $E 1$ and the other as E2. For Group BD, the bright light was E1, and the dim light was E2. For Group DB, this was reversed. For half the $S s$ in each group, E1 was on the right, and it was on the left for the others.

Each trial required $6 \mathrm{sec}$. The signal light was on for $1 \mathrm{sec}$, followed $2 \mathrm{sec}$ later by a reinforcing light that remained on for $2 \mathrm{sec}$. Following four practice trials, a series of 200 trials was given with $\pi=.7$.

\section{RESULTS AND DISCUSSION}

The mean proportions of Al responses (predictions of El events) over blocks of 20 trials are shown in Fig. 1. These learning curves suggest that luminance had an effect, with a preference being shown for predicting the brighter light. However, the scale of Fig. 1 exaggerates the differences between groups, and this conclusion was not generally supported by the statistical analysis. Comparison of the total Al responses in blocks of 10 trials over the 200 trials for the three experimental conditions yielded $F(2,96)<1.0$. There was a significant Groups by Trial Block interaction $[F(38,1824)=2.92, p<.001]$. This led to a simple effects test on the last block of 10 trials, on the assumption that this should best represent asymptotic responding, but there were no significant effects due to luminance conditions.

The number of $A 1$ responses over the last 40 trials was also analyzed, as a broader measure of stabilized responding, but there was no significant effect of luminance $[F(2,96)<1.0]$. At most, it could be said that once responding had stabilized fairly well, luminance had no significant effect, but it may have had an effect upon rates of learning.

In spite of the lack of overall significance over the last 40 trials, a test used by Nazzaro and Todorov was performed that compared only the $\mathrm{BD}$ and DB groups. This result was not significant $[t(78)<1.0]$. Finally, comparisons were made separately for each group of the differences between proportions of $\mathrm{Al}$ responses over the last 40 trials and the hypothetical asymptotic proportion of 7 . Groups DB and BB yielded $t(39)<1.0$, but Group BD, for which the brighter of the two lights was the $E 1$ event, yielded $t(39)=5.72, p<.001$, lending some support to Nazzaro and Todorov's results.

Recency effects over the last 40 trials were also examined, with both $A 1$ and $A 2$ showing negative recency, i.e., increased run lengths of E1 of E2 occurrences decreased the probability of A1 or A2 responses, respectively. However, the magnitude of the recency effects did not differ markedly between the main experimental groups.

Overall, considering the evidence in the present study and that of Boudewyns and Madison, it appears that if the luminance effect exists it is a weak effect.

However, these negative results may have been due to differences in experimental procedures. Nazzaro and Todorov used a self-paced task, where the reinforcing light on each trial served as a signal to begin the next trial. Both Boudewyns and Madison and the present study used the conventional Estes and Straughan procedurp, with fixed interstimulus intervals and a distinct signal to begin each trial. Moreover, $S s$ in the Nazzaro and Todorov study were informed $0.2 \mathrm{sec}$ after each response of the reinforcing event for that trial, while in the procedure used here the delay in reinforcement could be as long as $3 \mathrm{sec}$, depending upon how soon $\mathrm{S}$ responded following the onset of the signal. Thus, it is possible that with minimal delay in reinforcement the luminance effect can be obtained reliably, while a delay in reinforcement somehow eliminates the effect sufficiently to make it unreliable. This possibility is now being investigated.

\section{REFERENCFS}

BOUDEWYNS, P. A., \& MADISON, H. L. Luminance as a reinforccment parameter in probability learning. Joumal of Experimental Psychology, in press.

ESTES, W. K., \& STRAUGHAN, J. H. Analysis of a verbal conditioning situation in terms of statistical learning theory. Journal of Experimental Psychology, 1954, 47, 225-234.

MADISON, H. L., \& BOUDEWYNS, P. A. Asymmetric-reinforcing events in probability learning. Journal of Experimental Psychology, $1967,74,492-499$.

NAZZARO, J. R., \& TODOROV, J. C. Influence of luminance on a two-choice decision task. Journal of Experimental Psychology, 1966, 71, 696-699.

\section{NOTE}

1. Based upon the University of Wisconsin-Milwaukee MS thesis of the first author under the direction of the second author. This research was supported by grants from the University of Wisconsin-Milwaukee Graduate School. 